by heredity and environment in the development of the individual. A resemblance diagnosis has been established for determining the identity of similar sexed twins, and every case of identical twins is confirmed by identity of the blood groups. Examination of the after-birth of many twin births shows that identical pairs may have one chorion or two. Hair colour and eye colour are useful characters in diagnosing twins among Europeans, but not among Mongolian or African peoples, where these features do not vary appreciably. Identical twins are genetically identical persons, so that even skin transplantation can take place between them. All differences between such twins are therefore non-hereditary.

In a considerable study of tuberculous twins, extending over ten years, striking evidence has been obtained of the existence of an inherited disposition to tuberculosis. In several cases identical twins living for many years under very different conditions nevertheless sickened and died of the same form of the disease at almost the same time. In identical twins the number of concordant reactions to tuberculosis is very high compared with that of ordinary twins.

Inheritance in relation to numerous other diseases is being studied by recording all the twins in a given district and period, or by examining the twins among all the patients at certain clinics who are suffering from a particular disease.

\section{Chemical Bases of the Biological. Actions OF LIGHT}

The second exchange lecture was delivered on June 9 by Prof. R. Kuhn, of the Kaiser Wilhelm Institut für Medizinische Forschung, Heidelberg, and president of the German Chemical Society. Prof. Kuhn said that the elucidation of the mechanism of the many living processes in which light is concerned involves the application of well-established photochemical principles and experimental technique. As only light which is absorbed can cause a photochemical change (Grotthus-Draper law) one first looks for a photosensitive substance which absorbs light of the active wave-length. The correlation can often be confirmed by comparing quantitatively the 'action' (photosensitivity) curve with the extinction coefficient curve of the absorbing substance. In many cases the photosensitive substance is present in such minute amounts that careful extraction in the dark from a very large bulk of material is necessary in order to find it.

It is possible to make generalizations as to the types of organic structure which will lead to absorption in a certain part of the spectrum such as the visible. There are, of course, many examples of these types found in plants and animals. Furthermore, associated with these organic structures, there are certain types of photochemical change, such as cistrans transformations, shifts of the double-bond position, ring breaking, and production of free radicals.

It is a familiar fact that the higher green plants grow towards the light. The 'action' curve has recently been found to correspond to the absorption curve of carotine. The latter apparently photosensitizes the conversion of auxine- $a$, a growthpromoting substance, into an inactive lactone compound. On the sunny side of a plant the cell growth is therefore inhibited, while on the shady side it is not, hence the turning towards the light.

Gametes of Chlamydomonus eugametos in the light liberate a substance which sensitizes their copulation. This substance is found in high concentration in the stigma of Crocus sativus and is called crocin. The gametes are extremely sensitive to this substance, $0.4 \mathrm{mgm}$. in $10^{11} \mathrm{~cm} .^{3}$ being sufficient to activate them when their concentration is $2 \times 10^{6}$ per $\mathrm{cm}^{3}$. As the molecular weight of crocin is 978 , this corresponds to one molecule per gamete. A concentration a hundred times stronger is necessary before fusion between males and females takes place, but such a concentration is still far below the limits of detecting this highly absorbing substance by means of the eye. The specificity for the male and female species has been correlated with the cis and trans forms.

In fishes, the liberation in the dark of a lightsensitive substance, $1,2,3,4,5,6,8$ heptahydroxy, 7 . ethyl-naphthalene, by the ripe eggs chemotactically attracts the spermatozoa.

The photo-activity of human skin was studied by projecting the spectrum of a carbon arc on a test area for four minutes. The usual erythema maximum at $300 \mathrm{~m} \mu$ was found to develop after four hours, but a marked browning with maxima at 360,380 and $408 \mathrm{mu}$ developed in a much shorter time. The erythema at $300 \mathrm{~m} \mu$ disappeared in a few weeks, while that at longer wave-lengths persisted for some months. In a similar manner the 'action' curve of the ripening of a green banana skin was studied, and it was found to follow closely the absorption spectrum of chlorophyll.

Photosensitive substances, particularly visual purple, play a fundamental part in vision. The 'action' curve, that is, the luminosity curve, of scotopic vision follows closely the absorption spectrum of visual purple. A new colouring substance, astaxanthin, coupled to a protein, has been isolated from hens' eyes, and certain coincidences between its behaviour and phenomena occurring with colour vision may mean that it is associated with this visual process.

\title{
The S.S. British Queen
}

\begin{abstract}
A CENTURY ago, no journal displayed more interest in the progress of trans-Atlantic steam navigation than the Athenoum; and in its issue of June 22,1839 , it referred at length to the British Queen, which was built at the same time as the Great Western, but the completion of which had been seriously delayed. In June 1839, the British Queen was still in the Clyde, having her machinery
\end{abstract}

fitted by Robert Napier, and the Athenceum said: "The completion of this vessel is looked forward to with much anxiety by all who take an interest in the improvement and extension of steam navigation and all who desire the peaceful and reciprocally beneficial intereourse of eivilised nations. She will be most certainly a great experiment, in the theory of steam navigation, on many interesting points." 
The journal promised to give an account of the voyage of the ship from the Clyde to the Thames, and added to its article some notes from a "Scientific Correspondent" who had visited the ship. "Everyone admits," he wrote, "that she is a very handsome vessel; and perhaps the greatest proof of her symmetry is that as she reposes her leviathan bulk on the level shore, she does not appear so enormous as she really is. . . It was only when I gained the deck of the British Queen that I became thoroughly impressed with the truth of her enormous size. The deck is a long promenade, and the distance from stern to stem is a good rifle shot; her breadth on deck being some sixty feet. Descending to the engine room . . . looking up you perceive the men who guide the whole machinery and regulate and direct the combined strength and simultaneous energy of 500 horses, with greater success than the tyrant Philopater and his galley of 3,000 slave power, and feel that you are in the presence of one of the noblest of human creations. . . ."

The British Queen was built on the Thames at Limehouse by Curling and Young for the British and American Steam Navigation Company. This company had been founded through the efforts of the American lawyer and business man Junius Smith (1780-1853), who had been greatly assisted by Macgregor Laird (1808-61), the African explorer. She was $275 \mathrm{ft}$. long from figure-head to taffrail, $40 \mathrm{ft}$. 6 in. wide between the paddle boxes, and of 1,863 tons, being the largest steamship afloat. She had a twocylinder side-lever engine, with cylinders $77 \frac{1}{2}$ in. in diameter and $7 \mathrm{ft}$. stroke, driving paddle wheels $31 \mathrm{ft}$. in diameter.

\section{University Events}

BELFAST.-The Senate of Queen's University has decided to confer the following honorary degrees, among others: D.Sc. on Dr. J. H. Smith, until recently head of the Department of Engineering in the Belfast College of Technology; Doctor of Laws on Prof. F. H. Hummel, until recently professor of Civil Engineering in the University; $\mathbf{F}$. W. Ogilvie, formerly vice-chancellor of the University and now director general of the British Broadcasting Corporation.

Cambridge.-W. Campbell Smith, keeper of minerals in the British Museum (Natural History), has been approved for the degree of Sc.D.

Grasgow.-The King has been pleased, on the recommendation of the Secretary of State for Scotland, to approve the appointment of Prof. J. W. Cook, professor of chemistry in the University of London (Royal Cancer Hospital), to be regius professor of chemistry in succession to the late Prof. George Barger.

HuLl.-The following appointments and promotions, to date from October 1 , have recently been made: P. G. 'Espinasse, to be lecturer (grade A) in the Department of Zoology; Dr. W. B. Orr, to be lecturer (grade A) in the Department of Chemistry ; Dr. J. Bronowski, to be lecturer (grade B) in the Department of Mathematics; Dr. G. Tatham, to be lecturer (grade B) in the Department of Geography.

LoNDON.-G. W. Pickering has been appointed, as from October 1, to the University chair of medicine tenable at St. Mary's Hospital Medical School. Since 1930 he has worked at University College Hospital, being appointed as assistant in the Department of Clinical Research and, in 1936, as lecturer in cardiovascular pathology. In 1931 he was appointed a member of the permanent scientific staff of the Medical Research Council.

OXFORD.-The appointment of the first twelve fellows of Nuffield College, following on the appointment last year of its warden, Dr. H. B. Butler, marks the beginning of its corporate existence. The six faculty fellows, all of whom are fellows of existing Oxford colleges, are Mr. R. C. K. Ensor, Mr. J. Fulton and Miss Margery Perham, representing the political side, and Mr. G. D. H. Cole, Mr. R. L. Hall and Mr. R. F. Harrod, representing the economic. The six visiting fellows, whose task is "to assist those engaged in the University in research by giving them the fruits of their experience in practical affairs", are Lord Hailey, Lord Cadman, Sir Walter Citrine, Sir George Etherton, Mr. Claude Vickers and Mr. A. P. Young. In two years' time it is hoped that the buildings will be up and its gates open to the kind of persons for whom the College was intended. Apart from the fellows and the distinguished visitors for whom accommodation in the College will be provided, there will be forty students, all of whom will be reading for the degrees of D.Phil., B.Litt., or B.Sc., or engaged in some approved piece of research. These, if men, will be accommodated also in the College. It is expected that after 1941, Nuffield Colloge will become the centre in Oxford for all those who are concerned with the practical or theoretical treatment of social, economic and political problems.

\section{Societies and Academies}

\section{London}

Royal Society (Proc., A, 171, No. 945, 137-280, May 19, 1939).

Sir C. V. Raman and K. S. Venkata Raman : Determination of the adiabatic piezo-optic coefficient of liquids.

R. G. W. Norrish and E. F. Brookman: The mechanism of polymerization reactions. (1) The polymerization of styrene and methyl methacrylate.

E. V. Appleton and K. WeEkes: On lunar tides in the upper atmosphere.

K. G. Budden, J. A. Ratcliffe and M. V. WILkES : Further investigations of very long waves reflected from the ionosphere.

P. S. H. Hennry : Diffusion in absorbing media.

J. F. ALLEN and E. GANZ: Influence of pressure on the thermal conductivity of liquid $\mathrm{He}$ II.

G. P. Kane : Influence of nitrogen peroxide on the two-stage ignition of hydrocarbons.

H. Fröhlich, W. Heituer and B. KahN : Deviation from the Coulomb law for the proton.

\section{Edinburgh}

Royal Society of Edinburgh, May 1.

P. M. S. Blackett (Bruce-Preller address): The mesotron: the new unstable cosmic ray particle. Recent work both theoretical and experimental has 